\title{
BOAVENTURA CARDOSO E NEI LOPES: O REENCONTRO DE HERANÇAS FUNDADORAS
}

\author{
Rafael Domingues Lenz César”
}

\begin{abstract}
RESUMO: Este artigo compara obras do escritor brasileiro Nei Lopes e do escritor angolano Boaventura Cardoso, buscando ler algumas semelhanças, não apenas por serem escritas em língua portuguesa e apresentarem, mescladas, diversas palavras de origem banto, mas, principalmente, por trazerem visíveis marcas africanas, que persistem, ainda hoje, tanto na África, como no Brasil.

PALAVRAS-CHAVE: ficção angolana e brasileira; palavras de origem banto; raízes africanas.

RÉSUMÉ: Cet article se propose de comparer les cuvres de l'écrivain brésilien Nei Lopes et celles de l'écrivain angolais Boaventura Cardoso, cherchant à y voir des similitudes au delà $d u$ simple fait qu'elles sont toutes les deux écrites en langue portugaise et qu'elles y mélangent plusieurs mots d'origine banto, mais surtout parce qu'elles gardent de façon visible des marques africaines qui résistent, encore aujourd'hui, au delà du simple fait.
\end{abstract}

Mots-CLÉs: fiction d'Angola et du Brésil; mots d'origine banto, racines africaines.

Baile lá no morro é fandango / Nome de carro é carango / Discussão é bafafá / / Briga de uns e outros / Dizem que é burburim / Velório no morro é gurufim

(Padeirinho/Ferreira dos Santos)

Para dizerem milho dizem mio / Para melhor dizem mio / Para pior pio / Para telha dizem teia / Para telhado dizem teiado / / Evão fazendo telhados

(Oswald de Andrade)

A nossa língua é a nossa casa. Quando das primeiras expedições de europeus às terras africanas em busca de mão-de-obra escrava para a construção do Novo Mundo, os navios tumbeiros carregavam em seus porões uma variedade de deuses louvados, reis esquecidos e idiomas perdidos. As diferentes línguas africanas que, juntas, em espaços pequenos e abafados, atravessavam o Atlântico, teriam mais tendência a conflitos entre si do que a motins unidos, formando uma babel

"Bolsista de Iniciação Científica na Cátedra Jorge de Sena, com bolsa da Fundação Calouste Gulbenkian, durante o ano de 2007, sob a orientação da Prof. ${ }^{a}$ Dr. ${ }^{a}$ Carmen Lucia Tindó Ribeiro Secco. 
negra. É possível que, excetuando-se as não raras epidemias, o banzo tenha levado mais vidas do que qualquer outro evento ao longo das viagens. O banzo era a saudade de casa. $\mathrm{O}$ banzo era a saudade da língua.

Essas línguas, ao atracarem na outra margem do oceano, por vezes chegavam irmãs. Penetravam, então, novos contextos; conheciam outros povos; dissolviam-se em culturas alheias, agora também delas. Tanto em África como no Brasil, pelo contato com o português e com outros idiomas, ressignificavam-se. Nas margens brasileiras de cá e nas margens africanas de lá, mesclaram-se.

O presente ensaio se propõe comparar as estratégias usadas pelos escritores Boaventura Cardoso e Nei Lopes, respectivamente um angolano e um brasleiro, no uso que fazem da língua portuguesa em suas respectivas construções literárias. Para tal, partimos de duas reflexões do escritor português Helder Macedo no romance Partes de África e no ensaio "Sociedade pós-moderna, globalização e europeização do mundo português» que lidam, cada qual a seu modo e por diferentes vias, com as relações império-colônia, fronteira, globalização e internacionalização para uma visão sobre os caminhos da «língua portuguesa além-mar».

Helder Macedo apresenta uma posição política sobre as (desejáveis) relações entre Portugal e suas ex-colônias numa perspectiva cosmopolita; mais do que globalizante - como ele mesmo esclarece -, internacionalizada. Se a entrada de Portugal na comunidade européia foi, simbolicamente, um passo importante para que, após tantas gerações, se tornasse possível começar a desconstruir a imagem de Portugal como uma casa de eternos viajantes, à qual pouca atenção se deu em nome de impérios que teve e perdeu, lembra o ensaísta que é «chegada [...] a altura de fazerem as grandes obras na velha casa ancestral» ${ }^{1}$, para que os portugueses possam começar a sentir-se efetivamente europeus. Por outro lado, na contra-mão dessa vertente urge também assumir como legado de tantas viagens a condição de a cultura portuguesa possuir raízes para além de Europa. Em termos objetivos, um posicionamento que coloque também as outras nações de língua portuguesa como parceiras culturais.

Para Helder Macedo, é sobretudo pela noção de fronteiras que se devem pautar tais colocações, por entender, como escritor e crítico da cultura, que as fronteiras portuguesas não são apenas as geográficas conquistadas há séculos dentro da Europa, e que a própria idéia de uma União européia arriscaria a ver diluídas. Para problematizar uma questão que não pode ser elidida, ele pondera:

a abolição de fronteiras políticas e econômicas também pode levar a uma dissolução de fronteiras culturais. E creio que essa é uma fronteira que merece ser mantida. Não para fechar mas, pelo contrário, para que possa ser mantida aberta e transitável. As línguas e as culturas, que levam séculos a definir-se, podem desaparecer bem mais depressa. ${ }^{2}$

E se, como diz, com brilho de orgulho, que «A língua portuguesa [...] já não é apenas, nem sequer dominantemente, uma língua européia», parece-nos ser ela 
a chave para que culturas do «antigo ultramar português», cujo contato foi violento e intenso, se possam preservar - com suas constantes e inevitáveis transformações, mas mantendo assinaladas suas identidades -, e tenham a língua portuguesa como um visto de livre trânsito. Este aprendizado vem-se mostrando frutífero em duas das ex-colônias do ex-império. A começar por Angola.

Boaventura Cardoso, a par de sua vida política, soube reservar espaço para a produção de uma significativa obra literária. Seguindo os passos pioneiros de José Luandino Vieira, participou do percurso do que se pode chamar de nacionalização da literatura angolana. Tendo começado a escrever em tempos próximos à independência de seu país, e mantendo suas atividades literárias no pós-independência, deu continuidade a muitos dos temas que a geração anterior à sua abraçou, tanto no que se refere à denúncia social quanto a uma proposta de angolanização da forma estética. Exemplo disto é o tom já bastante inovador de Dizanga Dia Muenhu, livro de estréia do autor. Jorge Macedo procura definir a escrita de Boaventura referindo a sua «envolvente semântica, emergente da associação de gramáticas banto-européias, na fala do português angolano [...] reangolanizado [...], em razão da sua arte de tornar cada enunciado uma constelação de sentidos polissêmicos, fortes» ${ }^{3}$.

De fato, podemos encontrar nos contos de Dizanga Dia Muenhu estratégias várias que promovem a dramatização ficcionalizada de uma autêntica «fala» dos musseques luandenses. Em relação ao que Macedo chama de «gramáticas banto-européias», fenômeno bastante recorrente nos textos de Dizanga Dia Muenhu é a quimbundização do português. Para este caso, é especialmente produtivo o bilingüismo léxico como ocorre, por exemplo, em «Meu toque!»: «Esta sanzala grande onde vivemos - uns que ficam kilamas, outros castigo de monangamba - é que lhes arrastou na graxa ainda kandengue» ${ }^{4}$. Sanzala, kilamas, monangamba, kandengue são termos do quimbundo, cujos significados são nucleares no enunciado de tal modo que, sem sua compreensão, não se torna possível a depreensão do projeto significativo aí presente.

A quimbundização do português atua também sobre o plano sintático, gerando inversões por vezes estranhas às normas lusitanas que prescreviam para a língua portuguesa formas e usos mais castiços. No mesmo conto, a seqüência «Mulato filho de pula pai dele está onde? Mãe negra é mãe é pai» ${ }^{5}$ apresenta a anteposição de «mulato filho de pula» em relação a "pai», de quem se fala, como característica própria desses falares angolanos. O sintagma «é mãe é pai», por sua vez, imprime ritmo forte pela repetição da vogal aberta «e», em vez da cadência mais lenta que o sintagma «é mãe e é pai» possuiria - estratégias, por fim, em que Boaventura Cardoso insiste como formas de inserir, em seus contos, a diferença do falar coloquial dos musseques luandenses. Esta, porém, não é apenas representação de um modo angolano de falar, mas, sobretudo, um processo que busca a estetização da própria língua portuguesa. Boaventura cria, assim, uma «falescri- 
ta» angolana, conforme já observaram vários estudiosos de sua obra, entre os quais, por exemplo, Laura Padilha ${ }^{6}$.

Outro importante aspecto lingüístico é a inserção de características do campo prosódico no texto escrito. Apropriar-se de características e termos próprios da oralidade, recriando-os, é uma forma de apresentar marcas intrínsecas ao modo angolano de relacionar-se com a língua portuguesa. Exemplos disso são as interjeições ih!, eh!, eué!, éééé!, de alta recorrência, que aparecem em textos de Boaventura Cardoso, entre os quais o conto "Nos Tempos de Miúdo», e fazem, além do jogo descrito, clara referência não somente à fala do povo angolano, mas a vozes de antigos contadores de histórias, cuja sabedoria era oralmente transmitida às populações da região: «Traquinice nos tempos das férias? Eh! Se vos conto, me pagas quê, então? Bem. Era uma vez..., não me lembro mais. Ih!» ${ }^{7}$

A recriação da oratura presente em Dizanga Dia Muenhu busca pontos mais profundos para reinventar traços da identidade quimbunda na qual se baseia, não relegando apenas às marcas de oralidade a identificação com o modo africano tradicional de contar histórias. Uma das marcas mais importantes da transmissão oral do conhecimento é o investimento na reinvenção de fábulas, provérbios e desafios de adivinhaçãa. As situações concretas de ação e interação narradas encerram, sob o enunciado literal das histórias, lições-símbolos que explicam modos de conceber o mundo e a existência para a etnia quimbunda, um dos muitos grupos étnicos de Angola. Cabe ao interlocutor compreender e conferir às mesmas sua própria interpretação, constituindo, então, um caminho para a construção de seu conhecimento. Em um de seus muitos estudos sobre a presença das culturas negras no Brasil, Muniz Sodré conceitua: «O símbolo é como uma cebola que, arrancando-se uma após a outra as suas camadas, no final não tem nada, mas deixa as marcas da experiência corporal do descascamento. Tal experiência implica uma cultura.» ${ }^{8}$

Boaventura Cardoso evoca essa forma de organizar os saberes da cultura em alguns dos contos de Dizanga Dia Muenhu, fazendo a transposição para espaços urbanos. O conto «A chuva» abre a série contando uma situação de desavença entre o personagem Mano Zeca e o motorista do carro que lhe dá um banho ao passar em alta velocidade sobre uma poça d'água existente na pista. A confusão não tem final certo. Mas diz o narrador: «Mano Zeca, a cabeça nas mãos, pensava pensativo a chuva molha a terra, dá pão ao lavrador e canta alegria nos monandengues, traz também o vento das makas que os homens aplanam raivosamente de navalha em punho.» ${ }^{9}$

"Meu toque», conto seguinte, também ficcionaliza uma briga. Kaprikitu, kandengue pobre que trabalha lustrando os sapatos dos mais abastados pelas ruas de Luanda, ao abordar um cliente com seu bordão «sai graxa, freguês?», recebe de volta, gratuitamente, palavras de desagravo. Preocupado com as conseqüências da contenda que se ensaia, Kaprikitu pensa em como será seu dia seguinte. 
E o narrador, retomando o tom de crítica social que envolve o texto, finaliza-o: «O ódio não cresce se lhe cortarem a raiz.» ${ }^{10}$

Vale notar que tais assertivas têm importância para a formação do estilo de Boaventura Cardoso. Neste, encontramos a repetição de uma estrutura básica: enredos sobre situações concretas vivenciadas por habitantes de povoamentos de origem quimbunda, enredos estes que trazem formulações figurativas nas quais elementos da natureza - chuva, vento, raiz - se relacionam a vivências humanas a makas, ou seja, a situações de briga e discussão.

Os narradores de Dizanga Dia Muenhu não apenas reinventam um passado de oralidade, mas, agregando estas estruturas ao próprio texto inventado, criam um fazer literário com base na recriação do modo oral de relacionar-se com a contação de histórias. $\mathrm{O}$ uso de construções proverbiais presentes nessas contações corresponde à moral da fábula contada ou funciona como explicitação de um provérbio, de cuja lição a história narrada é exemplo.

A presença dos provérbios não é mero adendo ao texto. É, como indica Muniz Sodré em A Verdade Seduzida, uma herança cultural de origem africana que permanece, persiste como forma de relacionamento com o real. Este é um processo semelhante ao que possibilitou seguirem vivas e em constante evolução as origens negras do samba, sendo este, hoje, estilo musical de predileção dos brasileiros. Transformadas, adaptadas, estas partes de África podem sobreviver à lógica vigente de poder e ressurgem como formas de retorno à ordem lógica original.

A transcriação da tradição oral, que é matriz da cultura ficcionalizada pelos textos de Boaventura Cardoso, não se dá apenas por apropriações de formas de falar específicas, «ex-otizadas». Além do aproveitamento da variante da língua portuguesa em Angola, cujo ritmo inova a sintaxe do texto escrito, acompanha este fenômeno a apropriação de um modo de lidar com o mundo que é também relacionado à etnologia dos símbolos e mitos das culturas locais, responsáveis pela afirmação de sua identidade profundamente angolana.

De outro modo, na outra margem do oceano Atlântico, em sua já vasta produção intelectual e artística, Nei Lopes se desdobra entre a pesquisa sobre a contribuição dos saberes africanos, especialmente bantos, à formação do Brasil; a concepção de uma literatura brasileira de traços estético-estilísticos marcadamente negros; e a MPB (Música Popular Brasileira), que primeiro o levou ao público. As três vertentes em que trabalha guardam esta unidade de matriz negro-africana e se refletem, de modo bastante singular e inovador, em sua obra.

Em seus contos o autor parte da premissa de que os ambientes em que as populações negras se concentram no Brasil, como, por exemplo, os subúrbios cariocas, têm um modo mais marcadamente africano de estar no mundo. Não restam dúvidas: somos, os brasileiros, um tanto africanos; uns mais, outros menos. A alteridade das populações negras será revelada por Nei Lopes a partir 
da assunção, em sua literatura, da herança de uma tradição e de uma linguagem africanas.

Os estudos de Nei Lopes relacionados às influências das línguas de origem banto no português são usados na caracterização dos espaços apresentados em seus textos. O trabalho lingüístico impetrado surge como estratégia usada pelo autor para a criação dos cenários em que predomina a presença da população negra.

O primeiro resultado deste trabalho é a rica incidência, na língua portuguesa do Brasil, de vocábulos de étimo banto. Para tal exemplificação foram consideradas as propostas etimológicas do Novo Dicionário Banto do Brasil, do próprio Nei Lopes, e do Dicionário Houaiss da Lingua Portuguesa. Foram levantadas, nos contos «Gurumba Cúria Mataco», «Arroboboi» e "Dona Lili de Oliveira», as seguintes palavras:

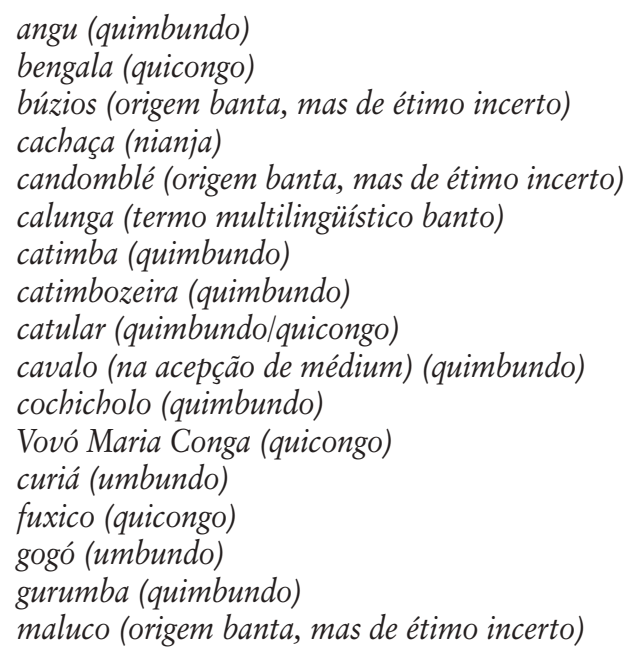

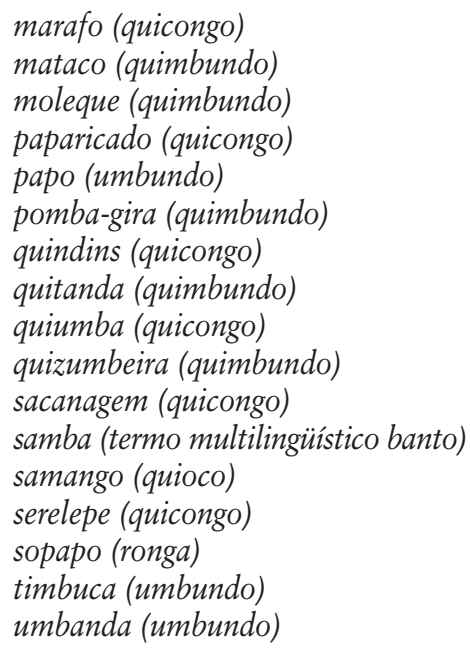

E, ainda, outras de origem africana não-banto:

$\begin{array}{ll}\text { afoxé } & \text { exu } \\ \text { axé } & \text { ialorixá } \\ \text { arroboboi } & \text { Houê Vevê Botchiô Vodun } \\ \text { Balogum } & \text { Ogunjá } \\ \text { Bessém } & \text { Oxóssi } \\ \text { Dan Ayidô Uedô } & \text { Oxumarê } \\ \text { ebame } & \text { roncó } \\ \text { egum } & \text { vodum }\end{array}$


É importante perceber que, diferentemente das palavras africanas de origem não-banto, as palavras do quimbundo, umbundo, quicongo, etc., não têm relação direta com as tradições religiosas ou com campos semânticos especificamente relacionados ao negro. São palavras incorporadas à língua portuguesa falada no Brasil nas mais diversas situações, mesmo as do cotidiano, e que são exploradas pelo autor na construção de seus textos. Diante disto, vale lembrar também que não há, neste caso, a situação de bilingüismo encontrada em Boaventura Cardoso. A linguagem dos personagens de Vinte Contos e Uns Trocados fala por ela mesma e, neste trabalho de auto-referenciação, cria uma ambientação de fundo (como uma voz em off) que não permite aos seus textos a desvinculação dos ambientes de forte herança cultural negra em que se encontram.

Sendo também os brasileiros herdeiros de diversas tradições orais africanas, as narrativas de Vinte Contos e Uns Trocados não hesitam em recriar formas oralizadas em variantes familiares faladas nos subúrbios e favelas cariocas. Em «Sujeito homem», por exemplo, o pai-narrador, lembrando a vida do filho assassinado por policiais no morro em que vivia, diz:

Inclusive, numa roda de partido, o moleque também não fazia feio, não. Mandava bem, uns versos malandreados, cheios de picardia. E de improviso, mesmo. Não era que nem esses malandros aí que diz que faz e acontece mas, na hora do vamo vê, só manda verso decorado. Ele era partideiro mesmo, no duro! Não deu foi sorte com esse negócio de gravação. Tu sabe como é que é isso, né? É uma tremenda ratatuia, mermão! ${ }^{11}$

Não é propriamente uma novidade o uso de construções deste tipo, sobretudo nesta virada de século que vem abrindo algum espaço para as manifestações dos «excluídos», nomeadamente os do grupo de escritores da dita literatura marginal contemporânea. A produção de Nei Lopes tem alguma convergência com a temática destes autores, porque, ao tratar de um universo cuja população é de maioria negra, inevitavelmente focaliza espaços pobres e, por vezes, faz a denúncia da violência, uma marca forte dessa geração de escritores. É necessário notar, contudo, que a apropriação deste tipo de linguagem em Nei Lopes não ocorre com a simples intenção de ficcionalizar realisticamente esses espaços, mas, principalmente, de valorizá-los e de fazer ressaltar o que pode identificá-los como locais relacionados ao negro. O determinante, portanto, é a afirmação dos valores negros, e não a pobreza, sua coadjuvante habitual na relação de causa e efeito. Uma evidência disto - ainda que tímida pela pequena recorrência - é o uso que faz destes falares, mesmo na voz dos narradores-observadores, e não somente nas «falas» dos personagens, assumindo, radicalmente, uma identidade negra. Em relação a este aspecto, merece atenção o conto «Dona Lili de Oliveira». A personagem é alegórica, sendo metonímia das tantas mães que têm de lidar com a situação de ter um filho envolvido com o crime: 
Bermuda colante, resgatando a identidade, o top de laicra balançando as melancias, lá vai Dona Lili pra cobrar cidadania das distintas autoridades.

- Assim é muita covardia! - grita ela, o celular pré-pago rebolando nas cadeiras.

Quando tem confusão, o que ocorre todo dia, ela, a grande líder, é sempre a primeira a chegar no D. P. O.

- O meu garoto é de menor!

Só que desta vez não é tão simples assim. E já faz mais de mês que o filho dela está na tranca:

- Esses polícia não se manca!

$[\ldots]$

E lá vai Dona Lili de Oliveira, cheia de democracia, o bustiê de laicra balançando as melancias. Vai comandando a passeata das comadres quizumbeiras, o celular pré-pago rebolando nas cadeiras... Excelentíssima Senhora Lili (de Liberdade) de Oliveira!!!... ${ }^{12}$

Os dois primeiros parágrafos da passagem acima transcrita são o exemplo de uma prosa quase-música. Apesar da disposição do texto em prosa, é muito evidente, pela sonoridade e ritmo da leitura, que se trata de uma estrutura com métricas regulares. Proponho a divisão dos parágrafos da seguinte forma, como se fossem versos:

Ber $\mid$ mu $\mid$ da $\mid$ co $\mid$ lan $\mid$ te $\mid$ res $\mid$ ga $\mid$ tan $\mid$ do a $i \mid$ den $\mid$ ti $\mid$ dade (13 sílabas poéticas) $o \mid$ to $|p|$ de $\mid$ lai $\mid$ cra $\mid$ ba $\mid$ lan $\mid$ çan $\mid$ do $\mid$ as $\mid$ me $\mid$ lan | cias (13 sílabas poéticas) A lá $\mid$ vai $\mid$ Do $\mid$ na $|\mathrm{Li}| \mathrm{li} \mid$ pra $\mid$ co $\mid$ brar $\mid$ ci $|d a| d a \mid$ nia (13 sílabas poéticas)

das $\mid$ dis $\mid$ tin $\mid$ ta $\mid$ s au $\mid$ to $\mid$ ri $\mid$ da $\mid$ des (8 sílabas poéticas)

A $\mid$ ssi $\mid$ mé $\mid$ mui $\mid$ ta $\mid$ co $\mid$ var $\mid$ dia (8 silabas poéticas) A

gri | ta e $\mid$ la o | ce $\mid$ lu |lar | pré| pa|go (8 sílabas poéticas)

re $\mid$ bo $\mid$ lan $\mid$ do $\mid$ nas $\mid$ ca $\mid$ dei $\mid$ ras (7 sílabas poéticas)

Quan $\mid$ do $\mid$ tem $\mid$ con $\mid$ fu $\mid$ são o $\mid$ que o $\mid$ co | rre (8 sílabas poéticas)

to $\mid$ do $\mid$ dia e $\mid$ la a $\mid$ gran $\mid$ de $\mid$ lí $\mid$ der (8 sílabas poéticas)

B

é| sem |pre a $\mid$ pri $\mid$ mei $\mid$ ra a $\mid$ che $\mid$ gar $\mid$ no $\mid$ D. | P. | O (12 sílabas poéticas)

$\mathrm{O} \mid$ meu $\mid$ ga $\mid$ ro $\mid$ to é $\mid$ de $\mid$ me $\mid$ nor! (8 sílabas poéticas) B

Excetuando-se a $2 .^{\mathrm{a}}$ linha do $3 .^{\circ}$ bloco e a $3 .^{\mathrm{a}}$ linha do $4 .^{\circ}$ bloco, cujas $7 \mathrm{e}$ 12 sílabas poéticas, respectivamente, tangenciam a métrica geral (sem, contudo, «quebrarem» o ritmo das frases) que se alterna em versos de 13 e 8 sílabas, há aí uma evidente realização musical. A importância desta invenção sonora na prosa está em ilustrar os movimentos da indignada Dona Lili a partir de um vozeado muito familiar aos redutos negros e suburbanos cariocas, cuja musicalidade mais conhecida é o samba. 
A alternância entre as vozes do narrador e a da protagonista funciona à semelhança da estrutura dos sambas de breque (cujo mais famoso representante terá sido, provavelmente, Moreira da Silva), em que há diversas interrupções (o breque), ao longo da música, com breves comentários rimados sobre o verso anterior. $\mathrm{Na}$ prosa-poética de Nei Lopes pode-se fazer a relação: a voz do narrador-observador opera como a letra do samba em si, e as intervenções de Dona Lili funcionam como o breque.

A militância estética de Nei Lopes e a de Boaventura Cardoso caminham paralelamente em busca de redesenhar a casa da palavra, de modo a captar ritmos e musicalidades das falas carioca e luandense. Se, por força dos contingentes históricos e sociais, as culturas letradas predominam em relação às de tradição oral, os conhecimentos que foram passados de boca a ouvido resistiram e ainda resistem na memória popular. Para a consecução de uma invenção literária significativa, atuam fundamentados no manejo das palavras e assertivas, de modo a moldar, no universo escrito, o conhecimento historicamente construído oralmente e a possibilidade de a encenação da transmissão oral pela escrita poder continuar seu curso, passando adiante saberes da tradição. Suas propostas estéticas são radicais ao revelarem um passado que se reclama vivo.

Helder Macedo vai a João de Barros, cronista da fundação do império português que, em 1539, imaginou um império menor para dali a certo futuro, mas no qual estaria ainda viva a língua portuguesa. E se, por um lado, atualmente, pode-se comprovar a pertinência de sua arguta hipótese, por outro seria o caso de indagar-se se ele teria também previsto tamanha inventividade com a língua para a qual escrevera uma gramática. E Helder Macedo prossegue:

Mas pelo menos, agora, o poeta moçambicano José Craveirinha já pôde publicamente reivindicar Camões como parte da sua literatura; no Brasil é mesmo a língua portuguesa que se fala, por muito que doa a quem ache que deve doer; e os portugueses já começaram a descobrir que a sua língua não é apenas aquela que julgam reconhecer. ${ }^{13}$

É também por isso que, mesmo sedeados em duas terras distantes - por mais que seus personagens não guardem com absoluta consciência as referências muito próximas que têm -, a par de estarem circunscritos a contextos sociais bastante distintos, os dois autores, Nei Lopes e Boaventura Cardoso, apresentam em suas obras algumas semelhanças que nos permitem fazer uma leitura dialogada entre seus textos, não apenas por serem escritos em língua portuguesa, mas, principalmente, por apresentarem visíveis marcas africanas, que persistem tanto na África, como na diáspora americana, o que torna visível o reencontro de heranças fundadoras dessas literaturas. 
${ }^{1}$ Macedo, H., 2007, p. 222.

${ }^{2}$ Macedo, H., 2007, p. 221.

${ }^{3}$ Macedo, J., 2005, p. 50.

${ }^{4}$ Cardoso, B., 1988, p. 16.

${ }^{5}$ Cardoso, B., 1988, p. 15.

${ }^{6}$ Padilha, L., 2002, p. 21.

${ }^{7}$ Cardoso, B., 1988, p. 49.

${ }^{8}$ Sodré, M., 2002, p. 17.

${ }^{9}$ Cardoso, B., 1988, p. 11.

${ }^{10}$ Cardoso, B., 1988, p. 17.

${ }^{11}$ Lopes, N., 2006, p. 167.

${ }^{12}$ Lopes, N., 2006, pp. 241-224.

${ }^{13}$ Helder, M., 1999, p. 245.

Cardoso, Boaventura. Dizanga Dia Muenhu. Luanda: União dos Escritores Angolanos, 1988.

Lopes, Nei. Novo Dicionário Banto do Brasil. Rio de Janeiro: Pallas, 2003.

- 20 Contos e Uns Trocados. Rio de Janeiro: Record, 2006.

Macedo, Helder. «Reconhecer o desconhecido». In: Gil, Fernando e Macedo, Helder. Viagens do Olhar. Porto: Campo das Letras, 1998.

- «Sociedade pós-moderna, globalização e europeização do mundo português». In: Trinta Leituras. Lisboa: Editorial Presença, 2007.

Macedo, Jorge. «Compromisso com a língua literária angolanizada na escrita». In: Chaves, Rita; Macedo, Tania; Mata, Inocência. Boaventura Cardoso: a Escrita em Processo. São Paulo: Alameda, União dos Escritores Angolanos, 2005.

Padilha, Laura. «Faca amolada: tradição e ruptura em Boaventura Cardoso». In: Novos Pactos, Outras Ficções. Porto Alegre: EDIPUCRS, 2002.

Sodré, Muniz. A Verdade Seduzida. Rio de Janeiro: Codecri, 1983.

- Mestre Bimba, Corpo de Mandinga. Rio de Janeiro: Manati, 2002. 